\title{
A REVIEW OF CO-MORBID DEPRESSION AMONG THE PATIENTS WITH ALCOHOL DEPENDENCE
}

\author{
Aman Kishore ${ }^{1}$, Manjeera C. H², G. Gopalkrishnan³ ${ }^{3}$ Agrim Bery ${ }^{4}$, Ram Ghulam ${ }^{5}$
}

\section{HOW TO CITE THIS ARTICLE:}

Aman Kishore, Manjeera C. H, G. Gopalkrishnan, Agrim Bery, Ram Ghulam. "A Review of Co-Morbid Depression among the Patients with Alcohol Dependence". Journal of Evolution of Medical and Dental Sciences 2015; Vol. 4, Issue 46, June 08; Page: 8078-8083, DOI: 10.14260/jemds/2015/1170

\begin{abstract}
Co-morbidity is "the occurrence of 2 or more distinct psychiatric disorders at the same time". Clinical and general population studies show that alcohol abuse or dependence and major depression often coexist. The presence of co-morbid conditions, such as alcohol dependence (AD) and major depression, has important implications for patient functioning and prognosis, including difficulties in case identification, treatment effectiveness and compliance, altered pharmacokinetics, and increased chronicity of both conditions. Although depression and alcohol dependence commonly coexist in community and treatment-seeking populations, there is no clear consensus on appropriate assessment and treatment of patients who present with symptoms of both disorders. To make appropriate treatment decisions, clinicians must know the likely effects of depression on drinking outcomes. This article reviews the relation between co-morbid depression and alcohol dependence.
\end{abstract}

KEYWORDS: Co morbid, depression, Alcohol use disorders.

INTRODUCTION: Alcohol is one of the most commonly used psychoactive drugs in the world. It is often difficult to clearly distinguish between the moderate or social drinking and excessive or harmful drinking.

India which had low levels of consumption of alcohol until recently is moving towards a higher level of alcohol use. The impact of western civilization and global cultural patterns seem to have accelerated this move in the last decade of the twentieth century. ${ }^{1}$

The diagnosis of major depression among actively drinking alcoholics is complicated by the fact that intoxication and withdrawal from alcohol and other substances can induce transient symptoms that mimic an independent depressive disorder. ${ }^{2,3}$

Keeping a note to different aspects of the co-morbid depression in Alcohol dependence, it will be appropriate to attempt to review the co-morbid depression associated with alcohol and its correlation with severity of dependence.

Alcohol use Disorders: Alcohol is consumed at some time up to $80 \%$ of the population. ${ }^{4}$ Heavy repetitive drinking, as seen in various alcohol use disorders (Alcohol abuse \& dependence), is found to be associated with significant morbidity and mortality in both genders, all cultural groups and all socioeconomic strata.

Alcohol use disorders (Alcohol abuse and dependence) are maladaptive patterns of alcohol consumption manifested by symptoms leading to clinically significant impairment or distress. The descriptive epidemiology of alcohol use disorders provides important evidence on treatment and prevention needs and informs hypotheses on biological and psychosocial causes of alcohol use disorders. 5

National survey for trends and patterns of alcohol and drug use in India revealed prevalence rate of alcohol use disorders to be $21.4 \%, 17 \%$ of them being dependent users. Studies done by 
Alcohol and Drugs Information Centre India, a non-governmental organization, in the southern state of Kerala revealed the percentage of the drinking population under 21 years has increased from 2\% to more than $14 \%$ in the past 15 years, and "average age of initiation" had dropped from 19 years to 13 years in the past two decades. ${ }^{6}$ A study conducted in Bangalore (India) found that nearly 33\% of the adult population regularly consumed alcohol. It also uncovered the fact that $2 \%$ of women also regularly consume alcohol; and in rural, slum and town areas, especially in select community groups, the proportions may rise up to the range of $5-6 \%{ }^{1}$

Co-morbid depression in patient diagnosed to have Alcohol dependence: Persons who have an Alcohol Use Disorder commonly suffer from other disorders at the same time. Often this is referred to as "Dual Disorder" and as "Double Trouble".

One recent study reported that $50 \%$ of women and $33 \%$ of males with a history of alcohol use disorders have at least one other psychiatric illness. ${ }^{7}$

Both major depression and alcohol dependence carry a significant risk for the development of each other. Severity in one disorder is associated with severity in the other. ${ }^{8-11}$ Moreover, alcohol dependence prolongs the course of depression, and persistent depression during abstinence from alcohol is a risk factor for relapse to heavy drinking.12-16

Recent estimates of the co-occurrence of these disorders in the general population are derived from the National Epidemiologic Survey on Alcohol and Related Conditions, a large-scale, nationally representative survey using DSM-IV diagnostic criteria. ${ }^{17}$ Data was collected from a sample of 43, 093 adults (18 years and older) who were interviewed between 2001 and 2002 to determine lifetime and current (past 12 months) DSM-IV diagnoses. For those with a diagnosis of current alcohol dependence, the prevalence rate for an independent major depressive disorder was 20.5\%. These alcohol-dependent individuals were 3.7 times more likely to have major depression than those without alcohol dependence. For those individuals with a current alcohol use disorder (abuse or dependence) who were seeking treatment, $40.7 \%$ had at least 1 current independent mood disorder.

Prolonged abstinence from alcohol can be of great value in making a distinction. Indeed, Brown and Schuckit ${ }^{18}$ demonstrated a significant drop in depressive symptoms for those with primary alcohol dependence who completed a 4-week inpatient program. Nonetheless, many patients have difficulty in abstaining from alcohol during outpatient treatment and eventually may drop out of treatment because of continued drinking and/or deepening depression. To this point, Greenfield and colleagues ${ }^{19}$ demonstrated that untreated depression-whether primary or secondary-predicted worse drinking outcomes. Finally, while depression may precede or be precipitated by alcohol dependence, implying causation, there may be common risk factors for depression and for alcohol dependence. These include stressful events, psychological trauma, and genetic vulnerability that lead to co-occurring expression, without one disorder causing the other.

Several large studies that carefully assessed DSM-IV criteria have shown that the prevalence of primary independent depressive disorders (e.g., major depression) are more common than substance-induced disorders in individuals with alcohol use disorders. ${ }^{17,20}$ Furthermore, women who are alcohol-dependent and depressed are more likely to have an independent mood disorder than a substance-induced disorder.20

Misdiagnosis: How alcohol dependence is related to depression is not clear. Depression and alcoholism can present as two separate diseases and neither one protects the person against the other. 
Family, twin, and adoption studies indicate that there is substantial inheritability in the aetiology of alcoholism. ${ }^{21}$ Depressive illnesses also run in families and appear to have an important biological basis. Affective disorders and alcohol dependence may share a common risk factor or factors that may be familial. Therefore the presence of one disorder may indicate an increased risk of the second. ${ }^{22}$ For example, excess co-morbidity between bipolar disorder and alcoholism has been observed. The two disorders may share a common risk factor or factors that may be familial and therefore the presence of one disorder may indicate an increased risk of the second.22

Alcoholism may cause relapse in depressed patients and contributes to the course of the depressive illness. Depression, which has been successfully treated, may be relapsed by alcoholism. Psychiatric symptoms in patients with alcohol abuse may be temporally or medically related to acute intoxication, active disease, withdrawal, detoxification, and recovery. ${ }^{23}$ Alcohol can cause temporary affective symptoms even in subjects with no history of clinically relevant depression. ${ }^{24}$ Alcohol use produces the same subjective symptoms and objective signs required for the DSM-IV diagnosis of a Major Depression.

Measuring depression based on the Hamilton Depression Rating Scale, Brown et al reported $42 \%$ of inpatient male alcoholics scoring 20 or greater, with only $6 \%$ maintaining those scores after 4 weeks of abstinence and treatment. ${ }^{25}$ Dorus et al reported $32 \%$ of alcoholics had met criteria for Major Depression on admission and after 3 weeks of abstinence they measured a $50 \%$ reduction in depressive symptoms. ${ }^{26}$ Brown and Schuckit suggest dividing depressed alcoholics based on primary (symptom cluster which appeared first) and secondary (later appearing symptom cluster) qualifiers for the two diagnoses. After 3 week abstinence, the group with primary alcoholism/secondary depression showed a $49 \%$ reduction in depressive symptoms. The group with primary depression/secondary of alcoholism showed only a $14 \%$ reduction. ${ }^{25}$ Clearly there is a subset of depressed alcoholics who, if treated early with antidepressants, would falsely appear to have responded to the pharmacologic therapy.

Most recent studies are consistent with a continuum of alcohol-related problems and do not suggest the existence of separate aetiologies for alcohol abuse and dependence. ${ }^{27}$ While alcohol abuse and dependence may be related in a number of important ways, how alcohol abuse/dependence is related to depression is not as clear. Alcohol is a depressant drug, its direct depressant property is greater at higher doses or when blood alcohol levels are falling. These mood changes have also been demonstrated in the face of expectations that alcohol consumption will elevate mood. ${ }^{28}$ Other indirect depressant effects can also be attributed to the "alcoholic lifestyle". In chronic alcohol users the range of changes in mood, cognition, affect, and neuro-vegetative signs usually seen with depressive disorders may be entirely due to the effects of alcohol and drugs. Subjective complaints include sadness, dysphoria, hopelessness, worthlessness, self-blame, lethargy, and general mental demoralization. Objective signs include depressed affect, psychomotor retardation, and sleep, sex, or appetite disturbances. ${ }^{29}$

Depression can exacerbate alcohol abuse and most alcoholics entering treatment will exhibit significant depressive symptoms. Patients suffering from alcohol abuse or dependence often encourage misdiagnosis by acts of historical omission or absolute misrepresentation. Both depression and alcohol dependence are associated with considerable shame and stigma. Definitive laboratory testing is not currently available to help the clinician make a causative diagnosis and prescribe effective disease-specific treatment. However, no studies have shown that depressive disorders actually cause alcoholism. 
Early in the course of a depression, Schuckit suggests that patients display inconsistent drinking patterns and may actually consume less alcohol. Continued drinking in the phase of alcohol induced depression is a result of addiction to alcohol. ${ }^{30}$ A study done by Davidson in 1995 does not show statistically significant difference of SAD-Q score between depressed and non-depressed group. ${ }^{31}$

Depression can be considered a part of the natural course of addiction. Miller and Janicak consider depression associated with early recovery to be protective and healing. A grief reaction is considered normal and expected after a loss. Depression is an integral part of that process. The addict suffers losses of alcohol, drugs, or relationships. The benefit of treating that depression must be weighed against the risk of aborting a natural healing process. ${ }^{32}$

CONCLUSION: Alcohol is both depressant and a stimulant, depending on the level of consumption and time after drinking. Persons who are alcohol dependent are often misdiagnosed as depressed because many of the symptoms of alcohol dependence mimic depression. Some of these symptoms include reduced appetite, decreased energy and insomnia.

It seems that depression in the patients admitted for alcohol de-addiction is related to alcohol use, an antidepressant may not have any therapeutic impact beyond what abstinence would achieve. Identifying the cause of the depression in individuals with alcohol dependence has been thought to be important for determining the course of the disorder and the optimal treatment approach.

\section{REFERENCES:}

1. Gururaj G, Girish N, Benegal V. Burden and socio-economic impact of Alcohol- The Bangalore Study, Alcohol control series-1, WHO Regional office for South East Asia, 2006.

2. Schuckit MA. The clinical implications of primary diagnostic groups among alcoholics. Arch Gen Psychiatry. 1985; 42: 1043-9.

3. Schuckit MA. Genetic and clinical implications of alcoholism and affective disorder. Am J Psychiatry. 1986; 143: 140-7.

4. World Health Organization. A Summary of Global Status Report on Alcohol. Management of Substance Dependence, Non-communicable Diseases, WHO, June 2001; WHO: 1- 15.

5. Hasin and Deborah. Alcohol use disorders in the DSM-V: The task ahead. Addiction. 2007; 102 (10): 1535-7.

6. Raekha Prasad. Alcohol use on the rise in India. Lancet. 2009; 373 (January 3): 17-18.

7. Lapham, SC, Smith, E, C'de Baca J, Chang I, Skipper BJ, Baum G, Hunt WC. Prevalence of Psychiatric Disorders Among Persons Convicted of Driving While Impaired Arch Gen Psychiatry. 2001; 58: 943-9.

8. Kessler RC, Crum RM, Warner LA, et al. Lifetime co-occurrence of DSM-III-R alcohol abuse and dependence with other psychiatric disorders in the National Comorbidity Survey. Arch Gen Psychiatry. 1997; 54: 313-21.

9. Regier DA, Farmer ME, Rae DS, et al. Comorbidity of mental disorders with alcohol and other drug abuse. Results from the Epidemiologic Catchment Area (ECA) Study. JAMA. 1990; 264: 2511-8.

10. Gilman SE, Abraham HD. A longitudinal study of the order of onset of alcohol dependence and major depression. Drug Alcohol Depend. 2001; 63: 277-86. 
11. Grant BF, Harford TC. Comorbidity between DSM-IV alcohol use disorders and major depression: results of a national survey. Drug Alcohol Depend. 1995; 39: 197-206.

12. Hasin DS, Tsai WY, Endicott J, et al. Five-year course of major depression: effects of comorbid alcoholism. J Affect Disord. 1996; 41: 63-70.

13. Mueller TI, Lavori PW, Keller MB, et al. Prognostic effect of the variable course of alcoholism on the 10-year course of depression. Am J Psychiatry. 1994; 151: 701-6.

14. Greenfield SF, Weiss RD, Muenz LR, et al. The effect of depression on return to drinking: a prospective study. Arch Gen Psychiatry. 1998; 55: 259-65.

15. Hasin DS, Grant BF. Major depression in 6050 former drinkers: association with past alcohol dependence. Arch Gen Psychiatry. 2002; 59: 794-800.

16. Kranzler HR, Del Boca FK, Rounsaville BJ. Comorbid psychiatric diagnosis predicts three-year outcomes in alcoholics: a posttreatment natural history study. J Stud Alcohol. 1996; 57: 619-26.

17. Grant BF, Stinson FS, Hasin DS, et al. Immigration and lifetime prevalence of DSM-IV psychiatric disorders among Mexican Americans and non-Hispanic whites in the United States: results from the National Epidemiologic Survey on Alcohol and Related Conditions. Arch Gen Psychiatry. 2004; 61: 1226-33.

18. Brown SA, Schuckit MA. Changes in depression among abstinent alcoholics. J Stud Alcohol.1988; 49: 412-7.

19. Greenfield SF, Weiss RD, Muenz LR, et al. The effect of depression on return to drinking: a prospective study. Arch Gen Psychiatry. 1998; 55: 259-265.

20. Niciu MJ, Chan G, Gelernter J, et al. Subtypes of major depression in substance dependence. Addiction. 2009; 104: 1700-9.

21. Begleiter, H., Kissin, B. (eds): The Genetics of Alcoholism. New York. Oxford Press, 1995.

22. Maier W, Licterman D, Minges J, Delmo C, Heum R. The relationship between bipolar disorder and alcoholism: a controlled family study Psychological Medicine 1995: 25: 787-96.

23. Solomon J (1989). Alcoholism and psychiatric disorders. In HW Goedde \& PD Agarwal (Eds.) Alcoholism: Biomedical and Genetic Aspects. New York, N.Y. Pergamon Press pages 216-27.

24. Schuckit MA, Tipp JE, Bergman M, Reich W, Hesselbrock VM, Smith TL. Comparison of induced and independent major depressive disorders in 2, 945 alcoholics. Am J Psychiatry 1997; 154: 948-57.

25. Brown SA, Schuckit MA. Changes in depression among abstinent male alcoholics. Journal of Studies on Alcohol 1988; 52: 55-61.

26. Dorus W, Ostrow DG, Anton R, et al: Lithium treatment of depressed and nondepressed alcoholics. JAMA 1989; 262: 1646-52.

27. Prescott CA, Kendler KS. Genetic and environmental contributions to alcohol abuse and dependence in a population -based sample of male twins. Am J Psychiatry 1999; 156: 34-40.

28. Schuckit MA, Monteiro MG (1988). Alcoholism, anxiety and depression. British Journal of Addiction 83: 1371-80.

29. Miller NS, Ries RK. Drug and alcohol dependence and psychiatric populations: The need for diagnosis, intervention, and training. Compr Psychiatry 1991, 32: 268-76.

30. Schuckit MA. Alcoholism and affective disorder: diagnostic confusion: In Goodwin DW and Erikson CK (Eds): Alcoholism and Affective Disorders. New York: SP Medical and Scientific Books, 1979, 9-19. 


\section{REVIEW ARTICLE}

31. Davidson KM. Diagnosis of depression in alcohol dependence: changes in prevalence with drinking status. Br J Psychiatry 1995; 166: 199-204.

32. Miller NS, Janicak PG. Treatment of Comorbid Psychiatric Disorders. In NS Miller, MS Gold, And DE Smith (eds.): Manual of Therapeutics for Addictions. New York: Wiley-Liss. 1997.

\section{AUTHORS:}

1. Aman Kishore

2. Manjeera C. H.

3. G. Gopalkrishnan

4. Agrim Bery

5. Ram Ghulam

\section{PARTICULARS OF CONTRIBUTORS:}

1. Senior Resident, Department of Psychiatry, MGM Medical College, Indore, M. P.

2. DNB Resident, Department of Psychiatry, Sowmanasya Hospital \& Institute of Psychiatry, Trichy, Tamilnadu.

3. Professor \& HOD, Department of Psychiatry, Sowmanasya Hospital \& Institute of Psychiatry, Trichy, Tamilnadu.

FINANCIAL OR OTHER COMPETING INTERESTS: None
4. DNB Resident, Department of Psychiatry, Sowmanasya Hospital \& Institute of Psychiatry, Trichy, Tamilnadu.

5. Professor \& HOD, Department of Psychiatry, MGM Medical College, Indore, M. P.

\section{NAME ADDRESS EMAIL ID OF THE CORRESPONDING AUTHOR:}

Dr. Aman Kishore,

Senior Resident,

Department of Psychiatry, MGM Medical College, Indore, M. P.

E-mail: amankishore@rediffmail.com

Date of Submission: 29/05/2015.

Date of Peer Review: 30/05/2015.

Date of Acceptance: 01/06/2015.

Date of Publishing: 08/06/2015. 